\title{
USER SATISFACTION OF MEDICAL EDUCATIONAL SERVICES
}

\author{
Ivona Stoica ${ }^{1}$ \\ Olguţa Anca Orzan ${ }^{2}$ \\ Andra Dobrescu ${ }^{3}$ \\ Daniela Constantin ${ }^{4}$
}

\begin{abstract}
In a dynamic environment and a strongly focused on the needs and demand's consumer, any successful business is based on a complex analysis achieved by using marketing research. The paper's core represents a marketing research whose aim is to analyze user satisfaction of medical educational service. The quantitative marketing research was based on a statistical survey method, using a questionnaire as a collecting tool posted on a web platform for better access, visibility and transparency in completing the form. After the development of a professional training session on medical education, it has been developed a study regarding the participants' satisfaction in terms of quality, utility, informational content and presentations efficiency. We analyzed variables such as respondents' appreciation regarding the quality of materials received, the value information, the event capitalization by establishing relationships with tutors communication, quality service and appreciations regarding the location of medical training session, default services (accommodation, ambiental atmosphere), event quality the ground objective variables in medical education services satisfaction case study. This paper presents a multivariate analysis, based on correlations between variables measuring user satisfaction of services on medical education services which are the ground's conclusions and strategies to improve medical education services.
\end{abstract}

Keywords: satisfaction, medical education services, quantitative research, online questionnaire

JEL Codes: C12, C18, C31, C83, M31, 110

\section{Introduction}

Consumer preferences have known in the last decade a great evolution and by this background, the consumer behavior has been changed in a radical way. The developement of online environment conducted to an even more greater development.

Many people choose the virtual environment instead of traditional because it's easier, cheaper and more than 100 times personalised. Individualisation in online is unique becase this is the answer to all consumer tastes and preferences. Although the consumers are asking and receiving more online information in just one click distance. In the elearning system we can also introduce different teaching methodes based on virtual environment which is easier to personalise by bringing information on a flexible support. Now it's easier using virtual tours if haven't got the chance to visit New York. If you need for a book you don't have to seek throuh shelf, now you need only an Internet connection and a credit card. Consumers don't want to loose their precious time so the business enviroment has developed adapting to their wishes by coming to new ways of selling products and offering services closer to users. All these new ways to market products and services become available to consumers in the past about fifteen years as a result of modern communication

\footnotetext{
${ }^{1}$ Romanian American University, Romania, e-mail: stoicaivona@yahoo.com

${ }^{2}$ Carol Davila University of Medicine and Pharmacy in Bucharest, Romania, e-mail: olguta@gmail.com

${ }^{3}$ The Bucharest University of Economic Studies, Romania, e-mail: andra.dobrescu29@yahoo.com

${ }^{4}$ The Bucharest University of Economic Studies, Romania, e-mail: constantin_val.daniela@yahoo.com
} 
technologies. A very important aspect is that the needs of consumers and their behavior are understood at a higher level in the virtual environment versus the traditional environment (Schiffman \& Kanuk, 2009).

\section{Methodology research}

There has been developed a study, where the research team has to identify specific elements in conducting the training session in Timişoara, the issues that have acted positively on the participants but also adversely affected the knowledge of which will contribute to the continued conduct of such events in conditions improve and the constant satisfaction of participants.

Defined by the decision problem specified above, the quantitative research will aim to study the participants' satisfaction on the quality of materials and services provided at the training session held in Timişoara on 16 to 19 April 2013 under the project "Professional training for Implementing new technologies in the Health Care System "that will lead to quality improvement actions to be taken.

This event is the sixth training sessions held for the counties of western development region meaning Arad, Caraş-Severin, Hunedoara, Timiş.

The research seeks a better understanding of users' satisfaction in medical educational services held under the "Professional training for implementing new technologies in the health care system."

We followed the respondents feedback on the quality of materials received, the information submitted, recovering the event by establishing relationships and communication between participants and invited lecturers, quality of services and feedback on the venue of the training session, the default services (accommodation, mass, ambient), the quality of the event.

Based on the defined purpose the objectives will develop, which aim to identify specific information necessary to this scientific step. We defined the core objectives and the secondary objectives of the research.

The core objectives that results from the purpose of research aimed for knowing the following: identification of awareness of the "Professional training for Implementing new technologies in the Health Care System", identifying the respondents sources of information about the project "Professional training for Implementing new technologies in the Health Care System", identification of information sources on respondents for the training session held in Timişoara, establishing grounds for participation to the training session organized in Timişoara, determining the satisfaction degree of the participants in the training session held at Timişoara in terms of lecturers' professional prestige, quality presentations held by lecturers, novelty informational content provided in the lectures, the quality of services provided by the organizers.

Also, were pursued core objectives like identifying the appreciation degree of the respondents about the usefulness of participation at the training session, the information received, the quality of presentations, networking, organizing committee for the training session, determining the satisfaction degree of respondents on where the medical training session was held, establishing awareness of the respondents on the project website "Professional training for implementing new technologies in the Health Care System".

Regarding the secondary objectives, were pursued through the central objectives, meaning age, participation frequency to the training session, area of residence, education level, medical specialty, income, work unit in carrying out their work and identifying feedback 's respondents about the possible suggestions on organizing future training session or any other opinions to express attitude towards training session attended.

For this research, as it was a face-to -face, research information sources are primary sources. The sample recorded an amount of 107 respondents.

Regarding the face to face research, the research unit (unit will be under investigation) will correspond to the observation unit and will consist of physicians. For primary data, the survey unit 
(unit from which we collect information) will consist of individuals, under the circumstances, doctors working in various specialties within each unit studied.

The questionnaire was chosen to distribute to be filled among the participants as comfortable, with fresh information imprinted in memory and after their completion; the questionnaires were entered on the online platform www.esurveyspro.com to be recorded in the database and subsequently analyzed. Introducing questionnaires on the eSurveysPro platform is based and the principle of transparency and greater accuracy in database management.

Information provided by respondents went through a rigorous checking procedure, after which the database was exported to Office Excel, corrected and result in the exported specific software used in marketing research, SPSS 20.0.

After interpreting the information obtained from these sources will be obtained also an overview of the main satisfaction elements of interest in attending this medical training session held in Timişoara during the period 16th to 19th April 2013 at Timişoara Hotel.

Following the research approach has been studied the training session and sought the participants satisfaction degree in terms of event (area venue, parking, food service, catering, accommodation, ambient, atmosphere) but also in terms of educational quality of the event (reputation and preparing those who lectured to the training session, presentations quality, topics novelty and the provided information). Also were asked a series of information that served in the knowing purpose of respondents' demographic variables. It will be noted that the relationship between dependent and independent variables analyzed, how it will influence the level of education variable, the income variable.

The questionnaire was designed also online and it is still active so it can be can be viewed by clicking the link http://www.esurveyspro.com/Survey.aspx?id=cc069de5-8ad0-4938-bf3871e59f6800df.

The information requested in the questionnaire are both factual and opinion. The questions are closed one or multiple choice and mixed giving the respondent the possibility to answer correctly, if the choices were not satisfactory.

For data systematization layouts were made contingency tables, correlation matrix, which shows the relevant links for research purposes and will be the basis for formulating conclusions and new directions for improving user's satisfaction for medical educational services.

The period during which the data were recorded was 16th to 19th April 2013; they were collected from the participants, doctors in predetermined areas of the target group (Rheumatology, Internal Medicine, Immunopathology, Physiotherapy, General Medicine, Neurosurgery, Radiology, Orthopedics, Medical Imaging Dermatology, Gastroenterology and Endocrinology).

Information processing operation consisted of editing and coding the data obtained in the previous step. Editing includes the verification and correction of errors. Following this process will proceed to analyze the data according to the purpose of research and the type of scale used.

For the data analysis and interpretation will be used mainly, relative frequencies for easier interpretation of the distribution of the sample according to the investigated variables.

\section{Interpreting and analysing the data}

Regarding the awareness project "Professional training for implementing new technologies in the Health Care System", it can be seen that most respondents found out about the organization of this project through colleagues $(50.5 \%)$.

Regarding the 'reasons for participation in the training session' variable, $43 \%$ of respondents said they had participated mainly for personal development, $29.9 \%$ participated in news in the field of interest, $15.9 \%$ participated for the interesting thematic that was discussed during the medical training session. 


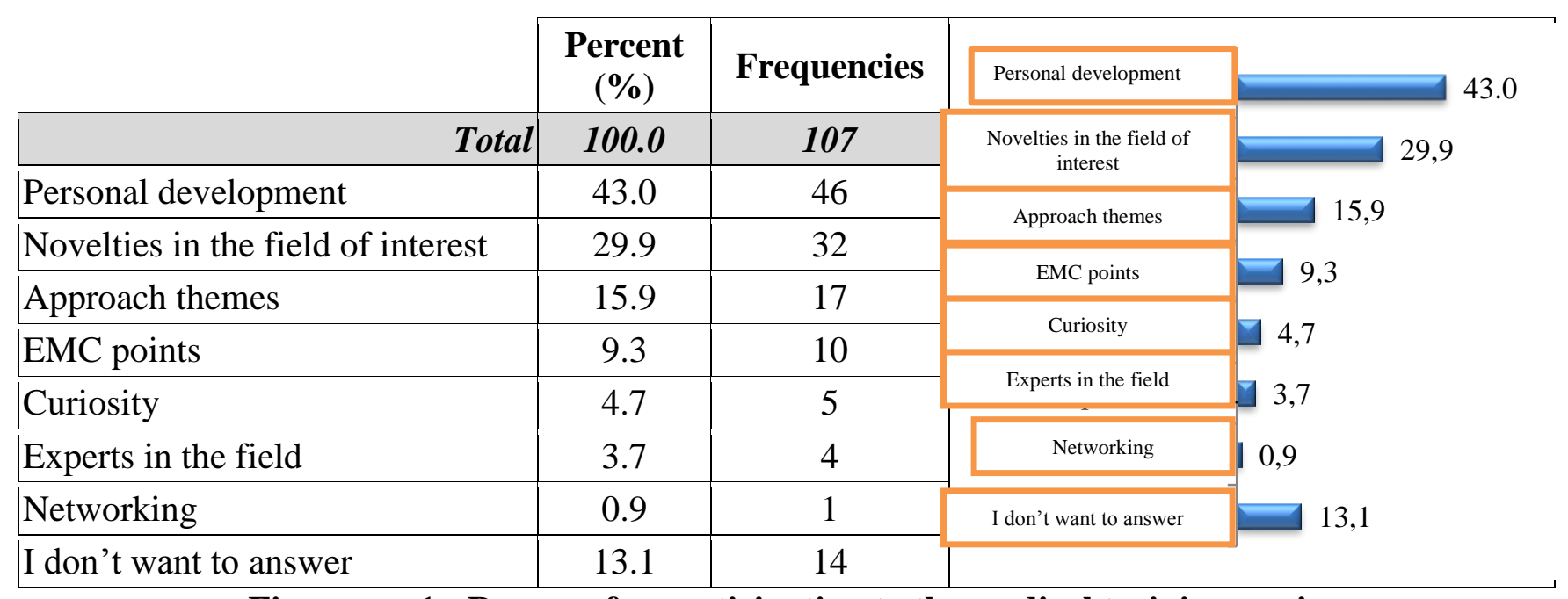

Figure no. 1 - Reasons for participating to the medical training session

Source: User medical educational services research report regarding training session satisfaction held in Timişoara, POSDRU/81/3.2/S/55648 "Professional training for implementing new technologies in the health care system", 2013, availble online at http://performed.ro/wordpress/wp-content/uploads/2013/03/Raport-Timișoara.pdf, accesed on september 20, 2013

The main reasons the respondents have wanted to attend this training session are related to their personal development (43\%), news (29.9\%) and themes (15.9\%) from the medical field shown in the event.

Table no. 1

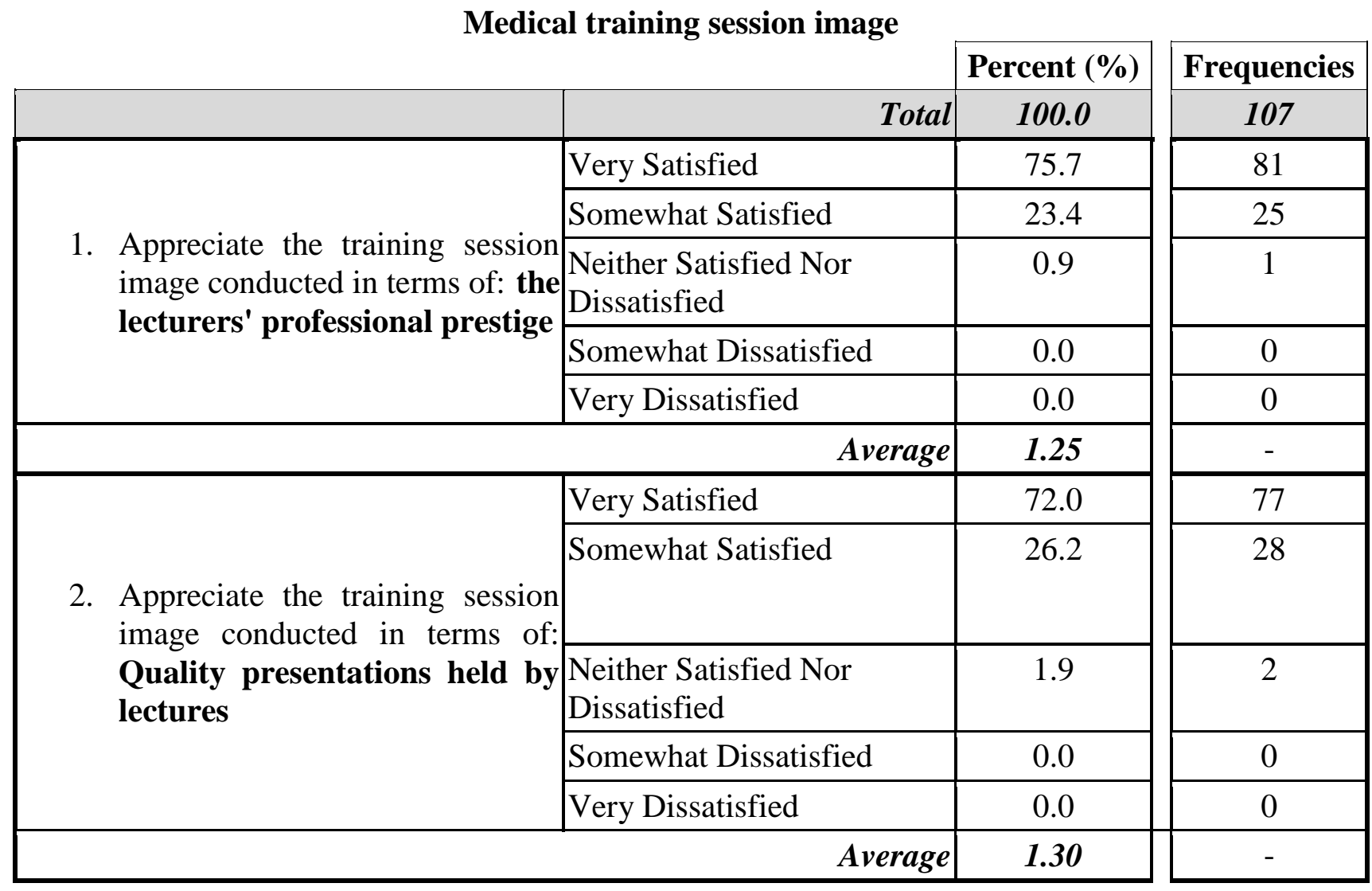




\begin{tabular}{|c|c|c|c|}
\hline \multirow{5}{*}{$\begin{array}{l}\text { 3. Appreciate the training session } \\
\text { image conducted in terms of: } \\
\text { Novelty informational content } \\
\text { offered }\end{array}$} & Very Satisfied & 59.8 & 64 \\
\hline & Somewhat Satisfied & 37.4 & 40 \\
\hline & $\begin{array}{l}\text { Neither Satisfied Nor } \\
\text { Dissatisfied }\end{array}$ & 2.8 & 3 \\
\hline & Somewhat Dissatisfied & 0.0 & 0 \\
\hline & Very Dissatisfied & 0.0 & 0 \\
\hline & Average & 1.43 & - \\
\hline \multirow{5}{*}{$\begin{array}{l}\text { 4. Appreciate the training session } \\
\text { image conducted in terms of: } \\
\text { Quality of services provided by } \\
\text { the organizers }\end{array}$} & Very Satisfied & 65.4 & 70 \\
\hline & Somewhat Satisfied & 29.9 & 32 \\
\hline & $\begin{array}{l}\text { Neither Satisfied Nor } \\
\text { Dissatisfied }\end{array}$ & 2.8 & 3 \\
\hline & Somewhat Dissatisfied & 0.9 & 1 \\
\hline & Very Dissatisfied & 0.9 & 1 \\
\hline \multicolumn{2}{|r|}{ Average } & 1.42 & - \\
\hline
\end{tabular}

Source: User medical educational services research report regarding training session satisfaction held in Timişoara, POSDRU/81/3.2/S/55648 "Professional training for implementing new technologies in the health care system", 2013, availble online at http://performed.ro/wordpress/wp-content/uploads/2013/03/Raport-Timișoara.pdf, accesed on september 20, 2013

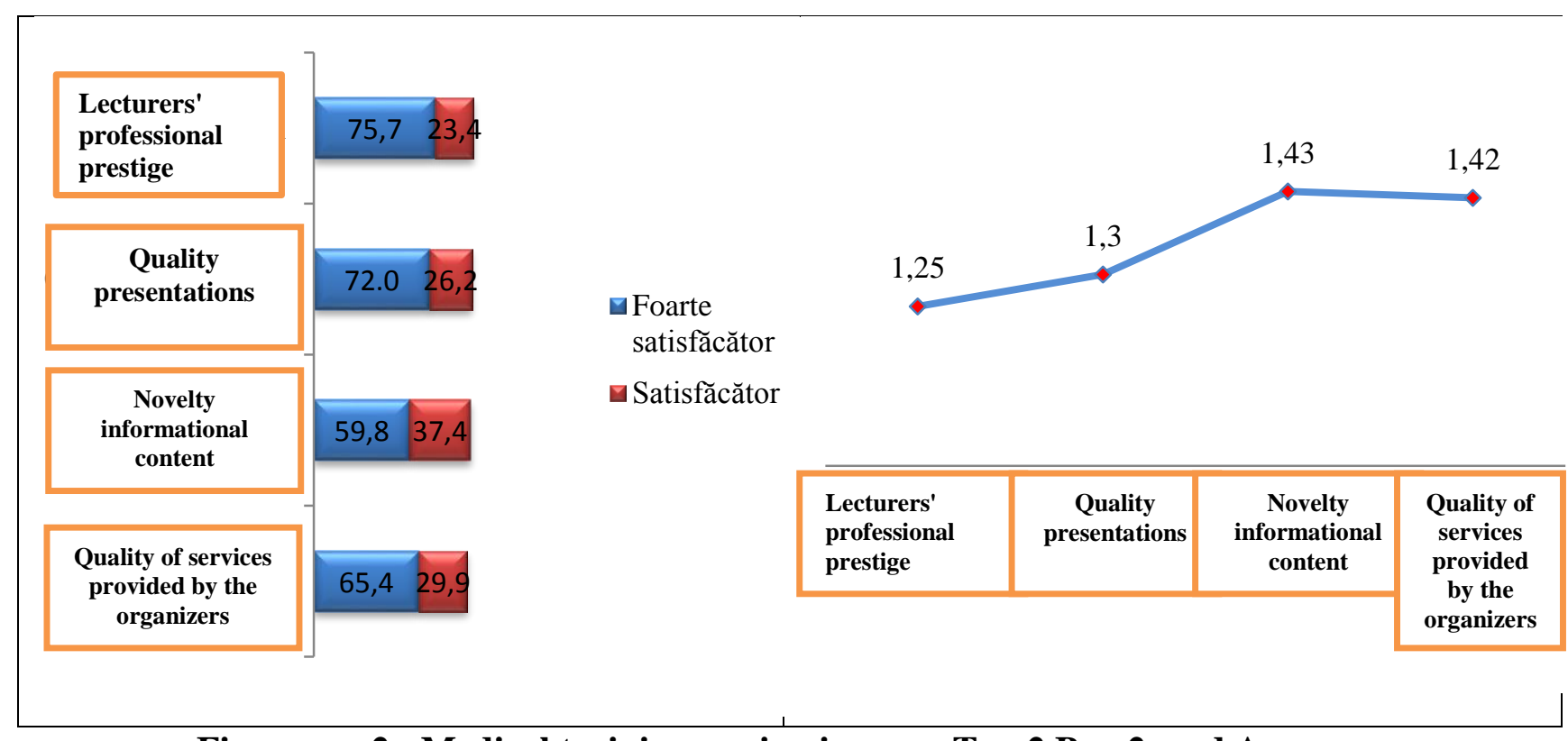

Figure no. 2 - Medical training session image - Top 2 Box 2. and Averages

Source: User medical educational services research report regarding training session satisfaction held in Timişoara, POSDRU/81/3.2/S/55648 "Professional training for implementing new technologies in the health care system", 2013, availble online at http://performed.ro/wordpress/wp-content/uploads/2013/03/Raport-Timișoara.pdf, accesed on september 20, 2013 
From the figures above it can be seen that the training session image created among respondents is Somewhat Satisfied, recording all aspects of average analysis (from 1-,,Very dissatisfieed" to 5 - "Very satisfied").

Professional prestige and quality lectures presentations are the main aspects that contribute to a positive image among respondents, over $70 \%$ of them saying they are very satisfied.

Medical training session image - Likert Scale

Table no. 2

\begin{tabular}{|c|c|c|c|}
\hline \multicolumn{4}{|c|}{ 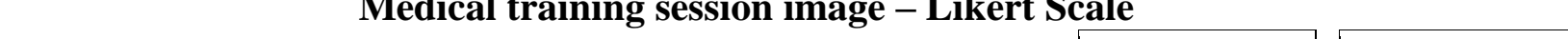 } \\
\hline & & Percents(\%) & Frequencies \\
\hline & Total & 100.0 & 107 \\
\hline \multirow{5}{*}{$\begin{array}{l}\text { 1. Appreciate medical training } \\
\text { session image: Participation in } \\
\text { the training session was } \\
\text { extremely useful }\end{array}$} & Strongly Agree & 63.6 & 68 \\
\hline & Agree & 36.4 & 39 \\
\hline & Undecided & 0.0 & 0 \\
\hline & Disagree & 0.0 & 0 \\
\hline & Strongly Disagree & 0.0 & 0 \\
\hline \multirow{6}{*}{$\begin{array}{l}\text { 2. Appreciate medical training } \\
\text { session image: I received } \\
\text { valuable information in my } \\
\text { field of interest }\end{array}$} & Average & 1.36 & - \\
\hline & Strongly Agree & 52.3 & 56 \\
\hline & Agree & 43.0 & 46 \\
\hline & Undecided & 3.7 & 4 \\
\hline & Disagree & 0.9 & 1 \\
\hline & Strongly Disagree & 0.0 & 0 \\
\hline \multirow{6}{*}{$\begin{array}{l}\text { 3. Appreciate medical training } \\
\text { session image: I was impressed } \\
\text { by the quality of presentations } \\
\text { at the medical training session }\end{array}$} & Average & 1.53 & - \\
\hline & Strongly Agree & 59.8 & 64 \\
\hline & Agree & 37.4 & 40 \\
\hline & Undecided & 2.8 & 3 \\
\hline & Disagree & 0.0 & 0 \\
\hline & Strongly Disagree & 0.0 & 0 \\
\hline \multirow{6}{*}{$\begin{array}{l}\text { 4. Appreciate medical training } \\
\text { session image: I enjoyed the } \\
\text { opportunity to establish links } \\
\text { with other prestigious guests }\end{array}$} & Average & 1.43 & - \\
\hline & Strongly Agree & 44.9 & 48 \\
\hline & Agree & 37.4 & 40 \\
\hline & Undecided & 15.0 & 16 \\
\hline & Disagree & 2.8 & 3 \\
\hline & Strongly Disagree & 0.0 & 0 \\
\hline \multirow{6}{*}{$\begin{array}{l}\text { 5. Appreciate medical training } \\
\text { session image: Organizing } \\
\text { training session was over my } \\
\text { expectations }\end{array}$} & Average & 1.76 & - \\
\hline & Strongly Agree & 56.1 & 60 \\
\hline & Agree & 40.2 & 43 \\
\hline & Undecided & 1.9 & 2 \\
\hline & \begin{tabular}{|l|} 
Disagree \\
\end{tabular} & 0.9 & 1 \\
\hline & Strongly Disagree & 0.9 & 1 \\
\hline & Average & 1.50 & - \\
\hline
\end{tabular}


Source: User medical educational services research report regarding training session satisfaction held in Timişoara, POSDRU/81/3.2/S/55648 "Professional training for implementing

new technologies in the health care system", 2013, availble online at http://performed.ro/wordpress/wp-content/uploads/2013/03/Raport-Timișoara.pdf, accesed on september 20, 2013

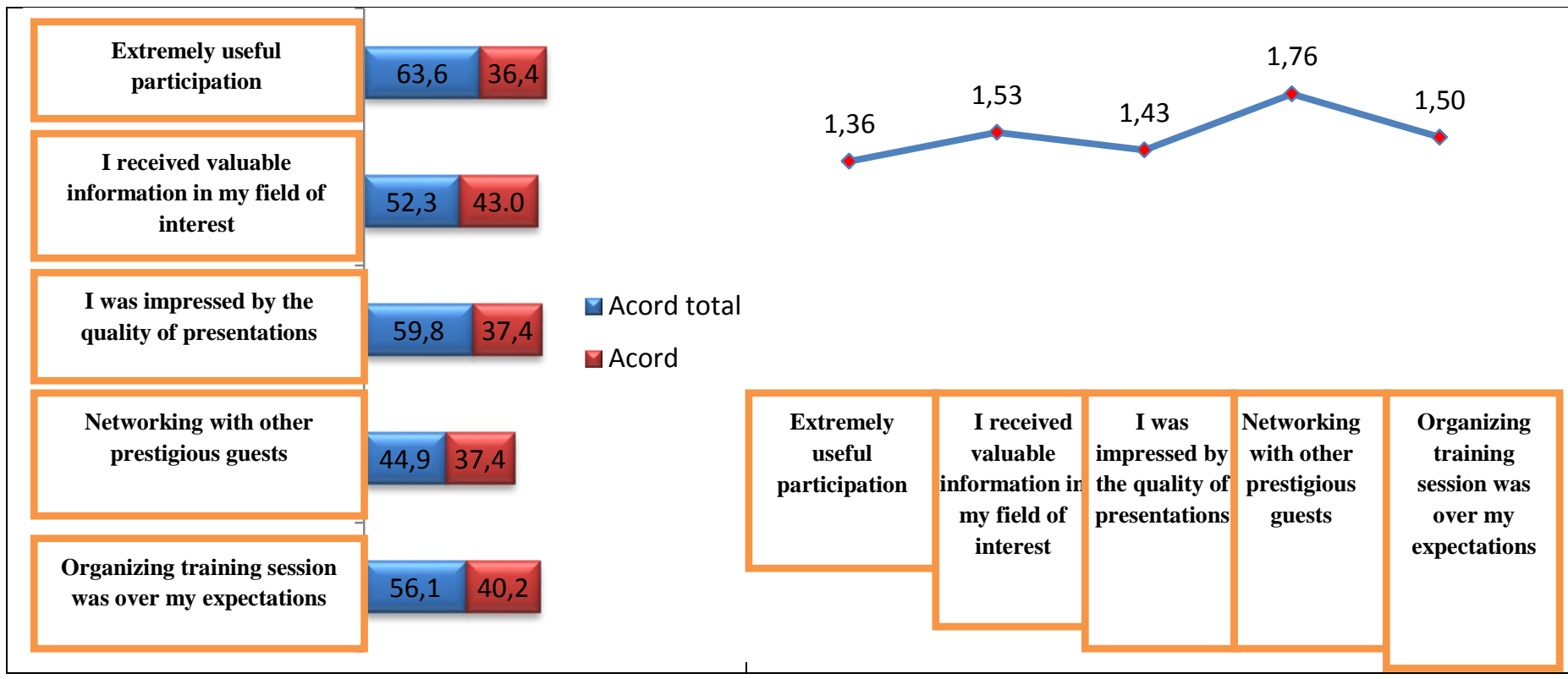

Figure no. 3 - Medical training session image - Top 2 Box and Averages - Likert scale

Source: User medical educational services research report regarding training session satisfaction held in Timişoara, POSDRU/81/3.2/S/55648 "Professional training for implementing new technologies in the health care system", 2013, availble online at http://performed.ro/wordpress/wp-content/uploads/2013/03/Raport-Timișoara.pdf, accesed on september 20, 2013

Regarding the respondents' assessment linked to the organization of the medical training session, they found that participation in this training session was very useful (1.36), were very impressed by the quality of presentations at the training session (1.43) the participants are arguing that organizing training session was over their expectations (1.50), consider to have received valuable information about the activity (1.53) and they consider that they received the opportunity to establish links other prestigious guests $(1,76)$.

\section{Conclusions}

Over $60 \%$ respondents are somewhat satisfied or very satisfied with aspects of the organization of the training session. In addition, the environment and equipment training session allocated in rooms and rooms availability are the main factors leading to satisfaction respondents when considering the medical training session location.

As for whether respondents are aware of www.performed.ro website, over $90 \%$ of respondents said that are aware, while over $80 \%$ have accessed at least once the PerforMed website.

Most participants in this training session are graduates $(80.4 \%)$.

Regarding participant age at Timişoara medical training session, most respondents $(37.4 \%)$ said they were aged between 26-35 years , 25.2\% say they have less than 55 years old, $21.5 \%$ are found in the age range 36-45 years, while only $15.9 \%$ of respondents said that they aged 46-66 years. 
No participant at the training session in Timişoara had aged 18-25. Over $80 \%$ of respondents are female gender, and $18.7 \%$ are male. Most participants in the training session are from Timiş county, respectively Timişoara. They also participated in the medical training sessions doctors from other counties such as Arad (7.5\%), Hunedoara (3.7\%), Caraş-Severin (1.9\%), Gorj, Bucharest and Mureş $(0.9 \%)$. The main sources of information accessed by the respondents before their participation in the training session held in Timişoara found information about the website project (www.performed.ro) through colleagues.

Most respondents found the organization of the professional medical training session in Timişoara by colleagues or friends, while about a quarter of all respondents were the main sources of information as the project website (www.performed.ro) or invitations sent directly to the work unit.

Most of the respondents participated in medical conferences nationally and internationally every 2-3 months or occasionally.

The main reasons why respondents decided to attend this medical training session is an opportunity to develop professional knowledge in the field and the curiosity for news on the topic addressed in the event.

In general, respondents have outlined a positive image about the medical training session. The professional prestige of speakers and quality presentations are the most important factors that contribute to the good image of the medical training session among respondents.

Respondents considered that participation in this medical training session were very helpful and were impressed by the quality of presentations at the event.

Two of three respondents said they were somewhere satisfied or very satisfied regarding the organization of the training session due to the ambience created at the event, fitting rooms and accessibility training session allocated.

Regarding the awareness of the project website, most respondents said they are aware of the project site, most of them accessing it at least once.

The main proposals / suggestions from respondents were addressing various topics and an increase of organizing these types of medical training sessions.

Regarding the demographic aspects of the majority of respondents, we registered women aged 26-35 years, with a net monthly income of at least 1,501 lei, have over 10 years of experience in the field and operate in an urban university hospital.

\section{Acknowledgement}

This work was cofinaced from the European Social Fund through Sectoral Operational Programme Human Resources Development 2007-2013, project number POSDRU/81/3.2/S/55648 "Professional training for implementing new technologies in the health care system".

\section{References}

1. Birks D. F., Malhotra N. K., 2007. Marketing research: An Applied Approach, Ed. a III-a, Harlow, Pearson Education

2. Brace I., 2004. Questionnaire design: How to plan, structure and write survey material for effective market research, London, Kogan Page

3. Cătoiu I. (coord.), 2009. Cercetări de marketing - Tratat, Bucharest, Uranus

4. Keller K. L., Kotler P. (2012). Marketing management, Ed. a XIV-a, New Jersey, Prentice Hall

5. ***User medical educational services research report regarding training session satisfaction held in Timişoara, POSDRU/81/3.2/S/55648 "Professional training for implementing new technologies in the health care system", 2013, availble online at http://performed.ro/wordpress/wp-content/uploads/2013/03/Raport-Timișoara.pdf, accesed on september 20, 2013 